\title{
Employee Ownership as a Solution to the SME Succession Issue: An Analysis of Furniture Industry Conversions to Employee Ownership in the United States, United Kingdom, and France
}

\author{
Carl Pitchford \\ Catholic University of Lille
}

Small and Medium-sized Enterprises play a significant role in global economic development. Therefore, it is vital that these family and founder-owned firms survive well into the future. This research presents an empirical approach to the issue of SME succession in three countries: the United States, the United Kingdom and France. It focuses on how founder-owners - mainly baby boomers looking to retire and sell their firms - transfer ownership of these firms based on the options available in those respective countries. This paper will analyse SME furniture manufacturing firms over the period from 2013 to 2019 which converted to employee ownership. This is definitely one way of preserving a firm's legacy, but offers no guarantee of success or even survival. Finally, my work is intended to go some way in supporting conversions to EO as a valid business model linked to more democratic ownership, continued legacy and firm survival for the benefit of all stakeholders, especially the employees and local communities. After all, employees are one of a firm's greatest assets.

Keywords: SME Founder-owner succession, conversions to employee ownership, SME survival, democratic ownership, furniture industry

\section{INTRODUCTION}

The objective of this work is to examine how converting conventional small and medium-sized enterprises (SME) manufacturing firms that convert to some form of employee ownership could solve the growing succession issue. The purpose will be to analyse conversions in general; however, the main focus will be to analyse conversions of existing founder-owned and family-owned SME furniture and accessory manufacturing firms where there is no apparent successor. This research paper will examine conversions that took place between 2013 and 2019, highlighting the survival rates of these firms based on financial ratio analysis. The conversions all took place in three countries: the United States, the United Kingdom and France. These three countries represent a hotbed of innovation in terms of alternative ownership models, of which employee ownership and worker cooperatives are the most common options.

The significant contribution of SMEs to local, regional and national economies should not be underestimated (CECOP-CICOPA, 2016). Globally, SMEs have long been considered as the main initiators of economic expansion and their reach and scalability are crucial to the very construction of a more 
democratic society. On average, these firms circulate three times more money back into local communities than absentee-owned businesses and corporate chains (NCEO, 2017).

The inclusion criteria for the research was further restricted so as to get a better appreciation of conversions to employee ownership accompanied by the survival rate of these transactions. The objective here is to focus solely on SME ownership succession due to retirement in the furniture manufacturing sector. There are specific conditions for employee ownership in the US, UK, and France with all three countries offering some variations on global models which include forms of an employee stock/savings option plan (ESOP), an employee ownership trust and a worker cooperative.

In order to assess the validity of the research, three case studies have been designed, adapted and anonymised from real-life conversions to employee ownership in the furniture industry in the US, UK, and France. Secondly, a financial analysis of 30 privately-owned furniture manufacturing firms from those respective countries has been carried out. In order to accomplish the objective, privileged access to the financial statements of all 30 firms has been obtained: 15 of which were converted to employee ownership, and the remaining 15 were either sold to a trade competitor or acquired by a private equity fund. Thirdly, interviews were conducted with expert practitioners in the three countries concerned by the research. The results of these interviews have provided insight into the topic of conversions to employee ownership, corroborating various aspects. Accordingly, the present paper is centred around the following alternative research hypothesis.

\section{LITERATURE REVIEW}

\section{Employee Ownership as a Route to SME Succession}

By opting to sell their firm to their employees, who usually live in the community, founder- owners help ensure that their business will remain rooted in the community (Abrams, 2008). Second, selling a business to employees can actually help provide the business with a competitive advantage when compared with investor-owned firms operating in the same marketplace - for instance, studies have indicated that workers are more productive in worker owned firms. More importantly, selling to employees may provide an exit possibility for the great number of business owners who plan to fund retirement through a business sale but are unable to identify a potential buyer. For business owners on the verge of retirement, the prospect of both preserving their business legacy while simultaneously decreasing the tax burden from the sale of their business should be quite alluring. In addition, the same tax law can also allow founder-owners to plan either a slow exit over a period of years or quick exit under the appropriate circumstances (Capital Impact Partners, 2018).

However, it is easier for founder-owners to achieve the tax benefit by converting to an ESOP than a worker cooperative in the US (Berner et al, 2015) as an ESOP can be implemented in two or three stages over a five-to-10-year period. Cooperatives, on the other hand, are conventionally and automatically structured as $100 \%$ employee owned. Financing a $100 \%$ leveraged conversion is extremely complex, especially when the founder-owners leave and take their management and leadership skills with them (Capital Impact Partners, 2018). Thus, it is vital for founder-owners to stay on in the converted firm for a negotiated transition period. An added advantage of this multi-phase worker cooperatives conversion is that the employee-members can still profit from the retiring founder-owners' ongoing management coaching a solid guarantee of firm survival (Blasi et al, 2013).

While investigating SME founder-owners' decision-making thought process regarding the retirement succession issue, two significant facts stood out in 2018. First, excluding firms owned by retiring baby boomers, there were more than 7,700 businesses under private equity ownership that will be coming onto the market in line with respective exit strategies. This will have an obvious impact as the competition for acquiring both types of firm will drive down valuation prices (Capital Impact Partners, 2018). There was and, still is, a definite lack of capital globally to cover all potential transactions, ignoring any possible conversion financing. Therefore, buyers will become extremely selective with only the best deals being completed and even then, acquisition value multiples will be negotiated downward. 


\section{Global Employee Ownership Conversion Potential and Market Assessment}

Closely-owned and, in particular, family-owned firms have, therefore, become increasingly conscious of the opportunities employee ownership can provide as a succession option and an alternative to a trade sale. In fact, for some founder-owners weighing-up the balance between financial and non-financial rewards has become the main driving force in selecting employee ownership over other options. Graeme Nuttall (2016) stated that the precise model a business will use in adopting employee ownership will differ according to the objectives of the business and the context. There are, however, two fundamental questions. First, is there is a willing founder-seller and second, is there a deal that works for them.

Abell (2014) described the ideal conventional firm candidate for conversion to a worker cooperative as having a long-term commitment to the business model, a good relationship between the owners and the employees, and a good business operations track record.

Therefore, apart from benefitting both firm and employees, the previous research would indicate that there is potential for employee ownership to increase economic stability while simultaneously reducing both unemployment and inequality in the economy as a whole.

\section{Employee Ownership and SME Survival}

One of the performance outcomes analysed in the literature are the survival and longevity rates of SMEs. Some authors have concluded that worker cooperatives will be shorter lived than conventional firms. Vanek (1975) claimed that dependence on internal financing from profit leads to under-investment. Employee-members have an incentive not to re-invest the profit in their cooperative, but instead claim higher wages which can ultimately lead to failure. Ben-Ner (1995) argued that worker cooperatives tend to degenerate into conventional firms because of a tendency to replace retired member-employees with nonmembers in order to increase remaining member employees' pay and benefits.

Empirical research does not lend much support to the degeneration of employee ownership. For instance, Huntzinger et al (2008) reported that more than 30\% of worker cooperatives in France are more than 30 years old. The authors found no evidence that worker cooperatives are less productive, less profitable or less capital-intensive than conventional firms, thus demonstrating that worker cooperatives can survive for long periods of time. Park et al (2004) suggested a number of reasons why employee-owned firms might survive longer than their conventional ones. Employment stability is an important factor which is measured through lower leaving rates, fewer redundancies, and greater investment in firm-specific training which all go towards improving performance.

Robinson and Zhang (2005) reiterated this notion adding that employee ownership helps protect investments in firm-specific knowledge and skills both for the firm and the employees. In fact, they argued that employee ownership can be a competitive advantage, as employee share ownership (ESO) enables firms to build and sustain their competitive advantage by rewarding and protecting employees. To that extent, it can be inferred that employee ownership improves firm performance and productivity and may even reduce the chances of bankruptcy and liquidation (Park et al, 2004).

Overall, there is clear evidence to show that employee ownership has a positive direct and indirect influence on the communities and regions where they operate (Berner et al, 2015). Employee ownership creates well-paid local jobs, develop skills and talent, and contribute significant financial and human resources that are crucial to the development of local communities. The values that employee ownership fosters encourage both employees and management to make decisions with the potential impact on the community in mind to an extent not usually observed in non-employee ownership (Blasi et al, 2013).

\section{Employee Ownership as a Route to SME Succession in the Furniture Industry}

In general, the furniture industry is capital intensive from the perspective of large-scale volume manufacturers for all types of segments and markets. However, there are many SME manufacturing firms which supply niche markets. They represent ideal candidates for conversion to employee ownership both in the US and Europe, particularly for worker cooperatives This type of industry has relatively low capital requirements, high labour requirements, and the potential for cooperatives to achieve high labour productivity (Ben-Ner et al, 1995). 
It is important to point out that there are no existing published academic or expert practitioner works or research in English concerning conversions to employee ownership in several countries and related to the furniture industry. This paper strives, therefore, to obtain a certain balance between contemporary works and historical works. So, 70\% were published during the period of the analysis between 2013-2019 and $30 \%$ were published prior to the analysis period. The expectation is that the findings of the research will go some way to bridging that gap.

\section{METHODOLOGY}

The methodology used in the research can be divided into three parts: interviews; conversion case studies, including an analysis of five key financial variables in order to measure financial performance before and after conversion; and the financial analysis and comparison of a sample of 15 conventional firms which converted to employee ownership and 15 conventional firms which were transferred to a trade competitor or private equity groups.

Financial ratios provide a clear indication of the robustness and resilience of a firm. However, in order to get a better understanding of a firm's financial health, it is necessary to combine different ratios into a worthwhile predictive model. In this research, regression analysis has been applied on past data to predict future values of a dependent variable. The discriminant analysis results in an index that allows classification of an observation into one of several groupings.

\section{Expert Practitioner Interviews}

Six expert practitioners with experience in the conversion process of conventional SMEs into employee-owned firms and, more specifically, worker-owned cooperatives have been interviewed. The panel was carefully selected so as to reflect their leading roles and innovative insights into all aspects of employee ownership from raising finance through to public policy formulation, and the desire to bring about more democratic business ownership. It included the following experts:

$>$ The President of the Employee Ownership Association (EOA) in the UK;

$>$ The Policy Officer at Cooperatives UK;

$>$ The Social Business Enterprise Director for Wales, UK;

$>$ The Founder of Cutting Edge Capital in the US;

$>$ The Capital Coordinator at Equal Exchange in the US;

$>$ A Regional Manager of the SCOP Worker Cooperative Network in France.

\section{Conversion Case Studies}

The case studies developed here meet the requirements of the different variables that were tested in response to the research hypothesis. Collectively, all the firms analysed are active solely in B2B markets. The three case studies are derived from real-life transactions that took place in 2013 and 2014. They draw attention to ways in which the transactions were structured and include a number of best practices which can be immediately applicable with regard to conversions to employee ownership as a succession solution for SME founder-owners in the furniture industry. The objective here was also to focus on different types of manufacturer:

1) A mid-market residential furniture manufacturer converting to an ESOP in the US.

2) A high-end residential and contract market manufacturer converting to an EOT in the UK.

3) A metal outdoor contract furniture manufacturer converting to a WC in France.

The objective when designing these three case studies was to construct validity. Firstly, through internal validity based on access to multiple sources in existing manufacturers that have converted or that are considering a conversion to employee ownership. Secondly, through external validity, the three case studies clearly illustrate that the data could be generalised to specific conversions in light of a global SME succession issue. However, the research indicates that the question is not so much to find cases that are generalisable to a broad population, as to find cases that are empirically instructive for all potential conversion projects. The final element is the reliability of the case studies themselves. This stems from the 
on-going examination and comparison in the three separate cases of the divergent factors to be taken into consideration in the three countries.

With access to the relevant financial documents and interviews, sufficient data was collected at the moment of the conversion and at least five years afterwards in 2018 and 2019 so as to analyse financial performance, focusing on five key financial variables.

1. Return On Assets: The ratio indicates how well a firm is performing by comparing the profit it is generating to the capital invested in assets. The higher the return, the more productive and efficient management is in utilising economic resources.

2. Return On Equity: This is a two-part ratio as it brings together the income statement and the balance sheet, where profit is compared to shareholder's equity. The number represents the total return on equity capital and shows the firm's ability to turn equity investments into profits.

3. Debt To Equity: This ratio calculates the weight of total debt and financial liabilities against total shareholder's equity.

4. Interest Coverage: This is a financial ratio that is used to determine how well a company can pay the interest on its outstanding debt.

5. Operating Margin or Return On Sales: This is a profitability ratio measuring revenue after a firm's operating and non-operating expenses have been covered.

The following vital success factors were also taken into consideration for this research. Firstly, the growth of the three separate furniture manufacturing sectors over the period analysed. Secondly, the founder-owner and employee mindset before, during and after the conversion. Finally, financial analysis based on certain key variables which were measured over a five-year period from 2013/2014 to 2018/2019.

\section{FINDINGS}

This section discusses the quantitative findings from the financial variables (as discussed above) in the three case studies and then the results from the hypothesis testing on the survival of furniture manufacturers once converted to employee ownership. Obviously, the outcome of the six interviews carried out was an overwhelming support in favour of more conversions of conventional firms to employee ownership in order to safeguard jobs and promote greater democratic firm ownership.

The table below is a summary of the findings from the five financial variables. These five key financial variables were used to prove the significant impact the conversion to employee ownership and employee ownership business model can have on a furniture manufacturing firm. The variables range from demonstrating employee-owner management efficiency regarding assets, capital, financial leverage, shortterm liquidity, and cost control.

TABLE 1

CASE STUDIES VARIABLES COMPARISON POST CONVERSION

\begin{tabular}{|l|c|c|c|c|}
\hline Variable & $\begin{array}{c}\text { Case Study 1 } \\
\text { conversion to } \\
\text { ESOP (US) }\end{array}$ & $\begin{array}{c}\text { Case Study 2 } \\
\text { conversion to } \\
\text { EOT (UK) }\end{array}$ & $\begin{array}{c}\text { Case Study 3 } \\
\text { conversion to WC } \\
\text { (FR) }\end{array}$ & $\begin{array}{c}\text { Global Furniture } \\
\text { Industry Average } \\
\text { (2018) }\end{array}$ \\
\hline
\end{tabular}

2018 values for each case are in bold to compare with the industry average

\begin{tabular}{|l|c|c|c|c|c|c|c|}
\hline & $\mathbf{2 0 1 8}$ & $\begin{array}{c}\text { \% } \\
\text { change } \\
\text { from } \\
\mathbf{2 0 1 3}\end{array}$ & $\mathbf{2 0 1 8}$ & $\begin{array}{c}\text { \% } \\
\text { change } \\
\text { from } \\
\mathbf{2 0 1 3}\end{array}$ & $\mathbf{2 0 1 8}$ & $\begin{array}{c}\text { \% } \\
\text { change } \\
\text { from } \\
\mathbf{2 0 1 3}\end{array}$ & \\
\hline Return On Assets & $\mathbf{1 5 . 2 \%}$ & $+68.6 \%$ & $\mathbf{9 . 2 \%}$ & $+37.3 \%$ & $\mathbf{5 . 0 1 \%}$ & $-38.3 \%$ & $\mathbf{5 \%}$ \\
\hline Return On Equity & $\mathbf{2 0 . 8 \%}$ & $+49.6 \%$ & $\mathbf{1 5 . 7 \%}$ & $+50.9 \%$ & $\mathbf{1 2 . 0 8 \%}$ & $-25 \%$ & $\mathbf{1 7 . 5 \%}$ \\
\hline
\end{tabular}




\begin{tabular}{|l|c|c|c|c|c|c|c|}
\hline Debt to Equity & $\mathbf{0 . 4 9}$ & $-43 \%$ & $\mathbf{0 . 6 1}$ & $-11.5 \%$ & $\mathbf{0 . 1 3}$ & $-50 \%$ & $\mathbf{0 . 4 0}$ \\
\hline Interest Coverage & $\mathbf{1 3 . 8 x}$ & $+23 \%$ & $\mathbf{1 3 x}$ & $+44.4 \%$ & $\mathbf{6 . 5 x}$ & $-50 \%$ & $\mathbf{4 x}$ \\
\hline Operating Margin & $\mathbf{8 . 3 \%}$ & $+15.2 \%$ & $\mathbf{8 . 6 \%}$ & $+4.8 \%$ & $\mathbf{7 . 3 \%}$ & $+8.9 \%$ & $\mathbf{1 1 \%}$ \\
\hline
\end{tabular}

Source: own $2013-2018$

\section{Analysis}

To begin with, an overview of the findings for the three case studies according to the specific employee ownership business model and the pre and post conversion to employee ownership ratio comparison results.

\section{Case Study 1}

The first case study involved a conversion to an ESOP. Return On Assets increased by $68.6 \%$ over the 5 -year period reflecting that each dollar spent by the firm grew profits. This result was also a tribute to efficient and productive management teams, not always so easy to attain in the furniture industry and has produced a higher than industry average figure. The Return On Equity also went up by almost 50\% over the period, illustrating that the firm obviously had a healthy competitive advantage. The debt-to-equity ratio went down which indicated that the firm has reduced its debt burden and is obviously using more equity to finance its capital investments. Interest coverage increased slightly and was still well above the industry average which is equally a good sign of financial robustness. Finally, operating margins also rose, but still below the industry average.

\section{Case Study 2}

The second case study involved a conversion to an EOT. Again, Return On Assets increased by just over 35\% reflecting that each pound spent by the firm had an impact on profits. This increase also related to the high-end niche market in which the was active. The Return On Equity grew by just over 50\% over the period which was completely understandable in light of its competitive advantage in the lucrative luxury and contract markets. The debt-to-equity ratio went down which indicated that the firm has reduced its debt burden and was obviously using more equity to finance its capital investments. With its healthy free cash flow position, it was noticeable that interest coverage increased by some $44 \%$ which was indeed 10 times the industry average. Additional proof that lucrative furniture markets can boost a firm's financial strength, especially in the case of a conversion to employee ownership. Finally, operating margins went up only timidly as a warning maybe that costs still needed to be controlled.

\section{Case Study 3}

The third case study involved a conversion to a WC. For this firm, completely different results were obtained in comparison with case studies one and two. Firstly, Return On Assets was down 38\%, but still within the industry average and Return On Equity was down $25 \%$ and below the industry average. For worker cooperatives, both these figures are always lower due to the social mission of the business which tend to invest more heavily in their employees rather than seeking out higher returns from assets and capital. Secondly, in line with these lower returns figure, the debt-to-equity ratio was reduced by $50 \%$ which again is typical of socially mission-driven firms. Thirdly, on a more worrying note, interest coverage also fell indicating that there was less cash available to reimburse debt, particularly in times of economic downturn. However, the figure was still above the industry average. Operating margins rose by $8.9 \%$, which was the second highest figure out of the three firms. So, ultimately, this WC was more effective in controlling its costs which is again in complete alignment with the international cooperative principles.

So, for both sample sets, the overall findings do represent business reality as well as continuity regarding firm culture and commercial acumen. Finally, in order to fully test the research hypothesis of this paper, a statistical t-test was carried out using the final Altman z-score results for both sample data sets which are outlined above. 
Based on the statistical findings, it can be stated that SME manufacturers have an equal chance of longterm survival whatever succession option is selected. Although, what could be argued is that the chances of long-term survival for furniture manufacturers could depend more on other non-financial and economic variables, but which are out of scope for this paper.

\section{CONCLUSIONS}

The research hypothesis began by juxtaposing two elements: the critical issue of succession for retiring baby boomer owners of SMEs and a potential solution by transferring ownership to the employees. The topic was elucidated with examples from the furniture industry. However, it was also vital to underline the major role played by SMEs in any economy, particularly in relation to growth and job creation.

This investigation was based on a detailed examination of various financial and non-financial variables, direct observation of firms and interviews with representatives of several international employee ownership associations and bodies. The main aims here were to challenge existing thinking and assumptions on the role of employee ownership as a valid business model and to put forward an alternative option. Taking into account prior research on all aspects of SME succession in general, the research aims to contribute to promoting the employee ownership business model as a practical solution to a specific problem.

This work, therefore, is intended to fill the existing gap as previously mentioned and serve as a guide for its intended readership.

Retiring SME owners in search of a solution could consider employees looking for a sustainable and viable buyout option, practitioners and professional advisors seeking transaction examples, success stories, best practices, and better international awareness of how to foster increased employee ownership in Europe, but also elsewhere. Impact investors who were not aware of employee ownership as an alternative asset class are another option.

Therefore, the ultimate contribution of this research is to put forward a financially sustainable, innovative and practical solution for all stakeholders. This paper concludes with two key messages. The first one concerns employee ownership and the second one concerns finance.

Firstly, employees are core creators of value in a firm, so they are one the most valuable assets. One of best ways of rewarding them is to transfer ownership of a healthy and stable firm and let them steer and steward it on the next journey. Secondly, access to capital and how that capital is used for employee ownership transactions will play obviously play a major role in helping to speed up the rhythm of conversions in the furniture industry or any other industry. However, in order to be successful, capital needs to be deployed in ways that are patient, risk-taking and replicated across industries while simulate employee ownership usually not being extractive or exploitative.

\section{LIMITATIONS AND RECOMMENDATIONS}

The intention of this paper is to propose some pragmatic solutions in a clearly under-developed research area. While it has provided an in-depth analysis based on the data available, it is by no means representative of all countries where SME succession is an issue due to retirement. However, it is important to emphasise that there is a need to gather more perspectives from a much larger sample of furniture manufacturing firms, for example, in more countries around the world. Together, these samples can be cross-referenced with the input from expert practitioners in order to examine any emerging trends that can all ultimately lead to one single objective: solving the SME succession issue.

To conclude the limitations part, failing to reject the null hypothesis is another way of stating that the results of the hypothesis testing were not statistically significant. The sample population selected did not provide sufficient evidence to conclude that the effect exists. However, at the same time, this lack of evidence does not indeed prove that the effect does not exist. So, it could be inferred that furniture manufacturers that did convert to employee ownership may indeed survive just as long or even longer than those transferred to the trade and private equity. 
The recommendation is to implement an innovative funding solution for founder-owners on the verge of retirement who want to convert their firms to employee ownership as an answer to their succession. The understanding of a recommendation is a critical suggestion on the preferred course of action in a particular situation. Hence, the proposal for a pan-European non-extractive patient capital investment fund focusing initially on the furniture industry in the short to medium-term, but with a view to replicating the fund to all potential activity sectors faced with retiring founder-owners and firm succession. Furthermore, a recommendation should provide an overview of how it will solve a certain issues, but also result in a beneficial outcome for all stakeholders.

New and innovative ways of financing conversions to employee ownership are being developed around the world, especially in the US. However, it is still too early to draw any conclusions on the success of such initiatives. A non-extractive patient capital investment fund is a strategic pragmatic response to the issue of SME succession. The aim is to begin solving the issue for the furniture industry and then replicate similar funds for other activity sectors. Such a fund structure could demonstrate that mission-driven capital can potentially bring about increased democratic ownership.

\section{REFERENCES}

Abell, H. (2014). Worker Cooperatives: Pathways to Scale. Democracy Collaborative. Working Paper. Abrams, J. (2008). Companies We Keep: Employee ownership and the Business of Community and Place. Ben-Ner, A., \& Jones, D. (1995). Employee Participation, Ownership, and Productivity. A Theoretical Framework. Journal of Econothe and Society.

Berner, C., Holmes, M., Reynolds, A., \& Rinehart, J. (2015). Case Studies and Key Factors for Success in the Conversion of Privately Held Businesses to Worker Cooperatives.

Blasi, J., Kruse, D., \& Weltmann, D. (2013). Firm Survival and Performance in Privately Held ESOP Companies. In Sharing Ownership, Profits, and Decision-Making in the 21st Century, Douglas Kruse, ed. Vol 14. In the series Advances in the Economic Analysis of Participatory and LaborManaged Firms.

Capital Impact Partners/Citi Community Development. (2018). Co-op Conversions at Scale. Working Paper.

CECOP-CICOPA. (2015). Cooperatives as Builders of Sustainable Development. Working Paper.

CECOP-CICOPA. (2016). Business Transfers to Employees Under the Form of a Cooperative in Europe: Opportunities and Challenges. Working Paper.

Hart, C. (1998). Doing A Literature Review: Releasing the social science research imagination. British Educational Journal.

Huntzinger, F., \& Jolivet, T. (2008). La Transmission d'Entreprises PME Saines en Coopératives Scop: Une Etude Exploratoire de Faisabilité en France.

Mselmi, N., Lahiani, A., \& Hamza, T. (2017). Financial Distress Prediction: The Case of French Small and Medium-sized Firms. International Review of Financial Analysis.

National Center for Employee Ownership (NCEO). (2017). Employee ownership and Economic WellBeing.

Nuttall, G. (2016). Simply Buyout. EMPLOYEE OWNERSHIPA. Working Paper.

Park, R., Kruse, D., \& Sesil, J. (2004). Does Employee ownership Enhance Firm Survival? Employee Participation, Firm Performance and Survival: Advances in the Economic Analysis of Participatory and Labour-Managed Firms.

Pendleton, A., \& Robinson, A. (2017). Employee ownership in Britain. White Rose Employee ownership Centre Working Paper.

Robinson, A., \& Zhang, H. (2005). Employee Share Ownership: Safeguarding Investments in Human Capital. British Journal of Industrial Relations.

Vanek, J. (1975). Self-Management: Economic Liberation of Man: Selected Readings. 